\title{
Developing Resident-Sensitive Quality Measures
}

Citation for published version (APA):

Schumacher, D. J., Martini, A., Holmboe, E., Varadarajan, K., Busari, J., van der Vleuten, C., \& Carraccio, C. (2019). Developing Resident-Sensitive Quality Measures: Engaging Stakeholders to Inform Next Steps. Academic Pediatrics, 19(2), 177-185. https://doi.org/10.1016/j.acap.2018.09.013

Document status and date:

Published: 01/03/2019

DOI:

10.1016/j.acap.2018.09.013

Document Version:

Publisher's PDF, also known as Version of record

Document license:

Taverne

Please check the document version of this publication:

- A submitted manuscript is the version of the article upon submission and before peer-review. There can be important differences between the submitted version and the official published version of record.

People interested in the research are advised to contact the author for the final version of the publication, or visit the DOI to the publisher's website.

- The final author version and the galley proof are versions of the publication after peer review.

- The final published version features the final layout of the paper including the volume, issue and page numbers.

Link to publication

\footnotetext{
General rights rights.

- You may freely distribute the URL identifying the publication in the public portal. please follow below link for the End User Agreement:

www.umlib.nl/taverne-license

Take down policy

If you believe that this document breaches copyright please contact us at:

repository@maastrichtuniversity.nl

providing details and we will investigate your claim.
}

Copyright and moral rights for the publications made accessible in the public portal are retained by the authors and/or other copyright owners and it is a condition of accessing publications that users recognise and abide by the legal requirements associated with these

- Users may download and print one copy of any publication from the public portal for the purpose of private study or research.

- You may not further distribute the material or use it for any profit-making activity or commercial gain

If the publication is distributed under the terms of Article $25 \mathrm{fa}$ of the Dutch Copyright Act, indicated by the "Taverne" license above, 


\title{
Developing Resident-Sensitive Quality Measures: Engaging Stakeholders to Inform Next Steps
}

\author{
Daniel J. Schumacher, MD, MEd; Abigail Martini, BS; Eric Holmboe, MD; \\ Kartik Varadarajan, MPH; Jamiu Busari, MD, PhD, MHPE; Cees van der Vleuten, PhD; \\ Carol Carraccio, MD, MA
}

From the Division of Emergency Medicine, Cincinnati Children's Hospital Medical Center (DJ Schumacher and A Martini); Office of the Chief Medical Officer, UCHealth (K Varadarajan), Cincinnati, Ohio; Accreditation Council for Graduate Medical Education (E Holmboe), Chicago, III; School of Health Professions Education (J Busari), Maastricht University, Maastricht, The Netherlands; Department of Educational Development and Research in the Faculty of Health, Medicine, and Life Sciences and School of Health Professions Education (SHE) (C van der Vleuten), Maastricht University, Maastricht, The Netherlands; and American Board of Pediatrics (C Carraccio), Chapel Hill, NC The authors have no conflicts of interest to disclose.

Address correspondence to Daniel J. Schumacher, MD, MEd, Division of Emergency Medicine, Cincinnati Children's Hospital Medical Center, MLC 2008, 3333 Burnet Avenue, Cincinnati, OH 45226 (e-mail: daniel.schumacher@cchmc.org).

Received for publication January 2, 2018; accepted September 24, 2018.

\section{Abstract}

OBJECTIVE: Despite the need for quality measures relevant to the work residents complete, few attempts have been made to address this gap. Resident-sensitive quality measures (RSQMs) can help fill this void. This study engaged resident and supervisor stakeholders to develop and inform next steps in creating such measures.

Methods: Two separate nominal group techniques (NGTs), one with residents and one with faculty and fellow supervisors, were used to generate RSQMs for 3 specific illnesses (asthma, bronchiolitis, and closed head injury) as well as general care for the pediatric emergency department. Two separate Delphi processes were then used to prioritize identified RSQMs. The illuminating similarities and differences that were explored through focus groups with residents and supervisors. These focus groups also probed future settings in which to develop RSQMs.

RESULTS: In the NGT and Delphi groups, residents and supervisors placed considerable focus on measures in 3 areas across measures produced by each group were compared side by side,

the illnesses of interest: 1) appropriate medication dosing, 2) documentation, and 3) information provided at patient discharge. Focus groups highlighted hospital medicine and general pediatrics as priority areas for developing future RSQMs but also noted contextual variables that influence the application of similar measures in different settings. Residents and supervisors had both similar as well as unique insights into developing RSQMs.

Conclusions: This study continues to pave the path forward in developing future RSQMs by exploring specific settings, measures, and stakeholders to consider when undertaking this work.

Keywords: outcomes-based assessment; quality care; resident assessment

Academic Pediatrics 2019;19:177-185

residency training on current and future patient care, performance feedback using quality measures should be guaranteed during these formative years. Although some quality measures used for physicians in practice are appropriate for trainees as well, many traditional quality measures are poorly aligned with resident contributions to care delivery. ${ }^{11,12}$

\section{Resident-Sensitive Quality Measures: Meeting a Need}

not well studied ${ }^{1}$ despite data showing an enduring correlation between the quality of care delivered during training and that provided in future practice. ${ }^{2-6}$ Investigations also demonstrate that many residency graduates are unprepared to meet the needs of patient populations, even for foundational tasks. ${ }^{7-10}$ Given the importance of
Despite the need for quality measures relevant to the work that residents complete, little has been done to address this need, ${ }^{11,13-15}$ limiting efforts to link resident performance with quality care delivery. ${ }^{16,17}$ This gap led us to develop "resident-sensitive quality measures" 
(RSQMs), which we define as "those measures that predictably require an action by the resident, with the resident possessing a realistic opportunity to do so, that directly impacts patient care in the clinical working and learning environment." ${ }^{, 18}$ The most effective process for developing RSQMs is not known. Therefore, determining a process for and developing additional RSQMs is important, as such measures are: 1) fundamental to assessing resident performance and providing formative feedback that fosters reflection on practice, 2) needed for orienting residents to care markers that can drive improvement in both training and practice, and 3) helpful in defining safe, effective, patient-centered care during training and beyond.

We previously described a method for developing RSQMs among faculty and fellow supervisors for use in the pediatric emergency department (PED) setting through consensus group methodologies for 3 illnesses (asthma, bronchiolitis, and closed head injury [CHI]) commonly seen in the PED. ${ }^{18}$ In this study, we replicate this process of developing RSQMs with residents and then explore similarities and differences in measures developed by residents and those developed by supervisors. Furthermore, we explore future settings in which RSQMs could be potentially useful, offering insights into best practices and next steps for developing RSQMs.

\section{Methods}

\section{Setting and Design}

This mixed-methods study used an explanatory sequential design involving 1) quantitative data collection and analysis, 2) qualitative data collection and analysis, and then 3) data interpretation. ${ }^{19}$ In the first study component, we sought to define and prioritize RSQMs for the PED by using the nominal group technique (NGT) and Delphi process with 2 distinct groups: residents and faculty/fellow supervisors. As noted, our work with supervisors has been described previously, with top-rated measures reported. ${ }^{18}$ The current study reports these measures in a different format with additional measures for the purposes of drawing comparisons between the 2 stakeholder groups. We followed these initial efforts with a qualitative study (focus groups with residents and supervisors) to explore differences between RSQMs resulting from the NGT and Delphi groups as well as future settings for RSQM development.

Participants for all study components were recruited via e-mail from residents at Cincinnati Children's Hospital Medical Center (CCHMC) as well as faculty and fellows from the divisions of emergency medicine (EM), hospital medicine (HM), and outpatient general pediatrics (GP) at CCHMC. All categorical pediatrics residents were considered eligible for all resident study components, but residents needed to have rotated in the PED to be included in the NGT or Delphi groups. Fellows and faculty in EM were eligible for the supervisor NGT and Delphi groups. Finally, fellows and faculty in EM, HM, and GP (described as best additional specialties to develop
RSQMs during resident focus group) were eligible for the supervisor focus group.

\section{Data Collection: NGT and Delphi}

Based on prevalence data and the desire to develop RSQMs for common, acute problems in the PED, we focused on acute asthma exacerbation, bronchiolitis, and CHI. ${ }^{20} \mathrm{We}$ followed the advice of Haan and colleagues ${ }^{14}$ to develop measures on a local level when existing national measures are insufficient. To accomplish this goal, we developed RQSMs locally using an NGT to generate measures, followed by a Delphi process to prioritize them. ${ }^{18,21}$ We completed this process with 2 groups separately: 1) pediatric residents and 2) faculty and fellow supervisors. By separating measure development and prioritization by group, we were able to explore similarities and differences between measures identified by each group. We recruited participants for the NGT and Delphi groups using guidelines from the literature ${ }^{20,22}$

\section{Nominal Group TeCHNIQUe}

Eight pediatric residents participated in the June 2017 session. Six pediatric emergency medicine faculty and fellows participated in the September 2016 session. At each session, participants were asked to generate potential quality measures for general care in the PED as well as for the 3 illnesses of interest. They were asked to consider measures that meet the following criteria: 1) important to quality care for a patient with the illness presenting in the PED, and 2) achievement of the measure likely represents work completed by the primary resident caring for the patient.

Participants individually recorded all ideas for potential measures in the 4 categories. After exhausting their lists, ideas were shared with the group in a round-robin format. NGT measure lists were edited for duplications and measures that could not be extracted from the electronic medical record (eg, verbal communication between a resident and nurse).

\section{DELPHI}

Most general PED care measures developed in the NGT groups applied to all 3 of the illnesses of interest. Thus, the relevant general care measures were added to the 3 specific illness measures to comprise the initial set of measures for rating in each Delphi process. A few additional measures also were added by the research team for round 1 of the supervisor Delphi process to expand on ideas generated from the NGT with this group. We believed these additions were acceptable because it is expected that researchers will need to clean and adapt items at the beginning of a Delphi group. ${ }^{23}$

We recruited 16 pediatric residents and 18 EM faculty and fellows for the resident and supervisor Delphi, respectively. For the resident Delphi, each round was completed within 2 weeks between June and July 2017. For the supervisor Delphi, each round was completed within 2 weeks between October and December 2016. 
In the first round of each Delphi, participants were provided with measures developed by their respective NGT group. They were asked to rate each measure on a 6-point scale, with 1 being the lowest rank and 6 the highest, in 2 categories: 1) importance of the measure to quality care for the specific illness, and 2) likelihood the measure represents work completed by residents. Participants could propose additional measures for rating if they desired. We defined consensus as a minimum of $80 \%$ of participants rating measures as a 5 or 6 in both categories for automatic inclusion into our final set. Measures that achieved automatic inclusion after each round were removed from rating in the subsequent round.

After round 1, participants were presented with their previous round ratings as well as the distribution of ratings from the entire group to inform the next round of rating. Sequential rounds continued for each Delphi process until lists of prospective measures met or exceeded our predetermined 10 to 15 measures per illness. In the final round, participants in each Delphi group were asked to prioritize their top 10 measures and next 5 measures (1115 ) for each illness.

\section{Data Analysis: NGT and Delph}

NGT and highly rated Delphi measures were compared side by side to determine differences and similarities in measures developed between the groups. In addition, final round Delphi measures were assigned a weighted score by allocating 2 points for each "top 10" rating and 1 point for each "next 5 (11-15)" rating. Thus, a measure could have a maximum score of 36 for the faculty and fellow Delphi (18 participants $\times 2$ points) and 32 for the resident Delphi (16 participants $\times 2$ points). Calculating this score allowed us to account differently for "top 10" and "next 5 " ratings in the final Delphi round to produce final rankings of measures.

\section{Data Collection: Focus Groups}

Subsequent focus groups explored differences between RSQMs developed by residents and supervisors as well as future settings in which to consider developing RSQMs (see Appendix A for interview guide). Participants were chosen for each focus group based on consensus of availability of potential participants who completed a poll after receiving the recruitment e-mail. The resident focus group included 8 residents and was held in July 2018. The supervisor focus group was also held in July 2018 and included 10 faculty and fellows (3 EM, $3 \mathrm{GP}$, and $4 \mathrm{HM}$ ). Focus groups were audio-recorded and professionally transcribed.

\section{Data Analysis: Focus Groups}

Focus group transcripts were analyzed using conventional content analysis, a method that derives codes from data and defines these codes during the analysis. ${ }^{22}$ Primary analysis was performed independently by $2 \mathrm{mem}$ bers of the team (D.J.S. and A.M.), who began by reading and rereading the data to gain immersion and then assigning codes. They used Dedoose (Version 8.0.35, SocioCultural Research Consultants, LLC, Los Angeles, Calif) to help facilitate coding. After independent coding of both focus group transcripts, they met to review codes and agree on a single set of codes. Working together, they grouped codes into categories that linked codes in meaningful ways followed by clusters that provided insights into: 1) why differences exist between residents and supervisors in their development of RSQMs and 2) what future settings should be considered for RSQM development. Secondary analysis was performed by another member of the research team (E.H.), who was provided both focus group transcripts, primary analysts' codebook, and the primary analysts' categories and clusters. This individual reviewed the transcripts to determine whether the primary analysts' coding, categorizing, and clustering accurately defined results from the data and did not include codes that were not clearly supported by the data. Primary and secondary coders collectively developed and agreed on final themes and results. NGT and focus group participants received $\$ 100$ for their time. Delphi participants received $\$ 150$, given the need for prolonged engagement and work. This study was determined to be exempt by the CCHMC Institutional Review Board.

\section{Results}

All participants in both NGT and Delphi groups completed all tasks for their group.

\section{Nominal Group Technique}

The resident NGT produced 150 measures: 57 general for PED, 33 asthma, 28 bronchiolitis, and $32 \mathrm{CHI}$. In the faculty and fellow NGT, participants generated 115 potential measures: 30 general for PED, 41 asthma, 16 bronchiolitis, and $28 \mathrm{CHI}$. As indicated in Table $1,{ }^{24}$ measures commonly focused on appropriate medication use, documentation, and information provided at discharge.

The NGT groups had 5 general PED measures in common (Table 1). In addition, the supervisor NGT participants had 2 measures focused on 48-hour returns that matched one of the resident measures (ED return/"bounce back" rate). Furthermore, the NGT groups had 4 additional measures that were very similar to one another for general PED measures. Similarities between groups continued for all 3 specific illnesses, as shown in Table 1.

\section{DELPHI}

The resident Delphi process began with 74 measures for asthma, 68 for bronchiolitis, and 79 for CHI. Table $2^{24}$ shows the top 10 measures based on the calculated score for each illness category. The supervisor Delphi process began with 67 measures for asthma, 46 for bronchiolitis, and 48 for CHI. The top 10 measures, based on the calculated score for each illness category, are shown in Table $3 .{ }^{24}$ As indicated in Tables 2 and 3, measures focused on appropriate medication use, documentation, 
Table 1. Similar Measures Produced from Faculty/Fellow and Resident Nominal Group Techniques

\begin{tabular}{|c|c|}
\hline Faculty/Fellows & Residents \\
\hline \multicolumn{2}{|c|}{ General pediatric emergency department care } \\
\hline Correct medication dose ordered* & Appropriate medication dosing ${ }^{*}$ \\
\hline Use interpreter if needed & Document use of interpreter if relevant \\
\hline Pertinent history documented $^{\dagger}$ & $\begin{array}{l}\text { Relevant history of present illness and medical history documented } \\
\text { in note }^{\dagger}\end{array}$ \\
\hline 48-hour return to ED for same illness & ED return/"bounce back" rate \\
\hline \multicolumn{2}{|l|}{ 48-hour return to ED with same illness with admit } \\
\hline Orders correct (labs, imaging) & Accuracy of labs/imaging ordered \\
\hline Finish chart in timely fashion ${ }^{\dagger}$ & Completion of all notes by end of shift ${ }^{\dagger}$ \\
\hline Reassessments of patient documented $^{\dagger}$ & $\begin{array}{l}\text { If time in ED is greater than } 4 \mathrm{~h} \text { after being assigned to resident, } \\
\text { reassessment of patient is documented }\end{array}$ \\
\hline Documented review of symptoms appropriate for billing level ${ }^{\dagger}$ & $\begin{array}{l}\text { Documentation supports disposition and billing level (eg, } 10 \text { review } \\
\text { of systems documented for admitted patients, number of physical } \\
\text { examination components documented for level of visit } \\
\text { complexity) })^{\dagger}\end{array}$ \\
\hline Call placed to referring MD during/following encounter & Documentation by resident when resident spoke with $\mathrm{PCP}^{\dagger}$ \\
\hline
\end{tabular}

Acute asthma exacerbation

Use PRAM appropriately (ie, initial orders match initial PRAM score) Documentation of number of exacerbations per year ${ }^{\dagger}$

Flu shot offered

Documented assessment of work of breathing ${ }^{\dagger}$

Documentation of asthma triggers for patient ${ }^{\dagger}$

Document response to treatment ${ }^{\dagger}$

Documented justification of imaging use/non-use ${ }^{\dagger}$

Avoid unnecessary chest radiograph

Documented follow-up plan in discharge papers

(eg, PCP in "X" number of days) $)^{\ddagger}$

Documentation of previous steroid use for asthma exacerbation ${ }^{\dagger}$

Documentation of relevant social history ${ }^{\dagger}$ (smokers in home, pets)

Documentation of spacer/metered dose inhaler for home

(either have it or order it) ${ }^{\ddagger}$
Resident assigned PRAM score matches resident placed orders

Documented asthma exacerbation history ${ }^{\dagger}$

Documentation of flu shot being offered if not up to date ${ }^{\dagger}$

Documentation of work of breathing ${ }^{\dagger}$

Documentation of presence or absence of potential triggers in housing environment (eg, mold $)^{\dagger}$

Reassessment documented in response to treatment ${ }^{\dagger}$

If chest radiograph ordered, justification is documented in note ${ }^{\dagger}$

Ensure primary care provider follow-up information documented in discharge papers ${ }^{\ddagger}$

Documentation of last steroid course (or no previous steroid courses) $)^{\dagger}$

Documented tobacco exposure ${ }^{\dagger}$

Give albuterol prescription and make sure enough albuterol for home and school ${ }^{\ddagger}$

\begin{tabular}{|c|c|}
\hline \multicolumn{2}{|c|}{ Bronchiolitis } \\
\hline Documentation of assessment of hydration status ${ }^{\dagger}$ & Hydration status clearly documented in note ${ }^{\dagger}$ \\
\hline Bulb suction teaching ordered & If disposition set to home, suction teaching for home ordered ${ }^{\ddagger}$ \\
\hline Documentation of previous hospitalization for bronchiolitis ${ }^{\dagger}$ & $\begin{array}{l}\text { Document presence or absence of previous admission for } \\
\text { bronchiolitis }^{\dagger}\end{array}$ \\
\hline Time to nasal suction order & $\begin{array}{l}\text { Time from resident assigning self to patient to placing nasal suction } \\
\text { order }\end{array}$ \\
\hline Frequent reassessments documented ${ }^{\dagger}$ & Minimum of 1 reassessment exam documented in note ${ }^{\dagger}$ \\
\hline No chest radiograph ordered & If chest radiograph ordered, justification is documented ${ }^{\dagger}$ \\
\hline
\end{tabular}

No chest radiograph ordered

Closed head injury

Documentation presence or absence of loss of consciousness ${ }^{\dagger}$ Appropriate PECARN/closed head injury pathway use

Documentation presence or absence of emesis ${ }^{\dagger}$

Full neurologic examination documented ${ }^{\dagger}$

Mechanism of injury documented ${ }^{\dagger}$

Return to school/play recommendations in discharge papers ${ }^{\ddagger}$

Appropriate follow-up (sports medicine, rehabilitation medicine, neurology, etc) recommended ${ }^{\ddagger}$

Follow-up with head injury clinic if concussion diagnosis given ${ }^{\ddagger}$
School/sport note at discharge about restrictions ${ }^{\ddagger}$

Presence or absence of loss of consciousness documented ${ }^{\dagger}$

Does PECARN best practice alert recommendation match what was done for the patient

Presence or absence of vomiting documented ${ }^{\dagger}$

Full neurologic examination documented ${ }^{\dagger}$

Mechanism of injury documented ${ }^{\dagger}$

Guidelines given for return to play ${ }^{\ddagger}$

Discharge papers document who to follow up with (primary care provider, concussion clinic, etc) ${ }^{\ddagger}$

Follow-up in concussion clinic recommended at discharge if appropriate for patient ${ }^{\ddagger}$

If diagnosed with concussion, school note given for rest and activity restrictions ${ }^{\ddagger}$

ED indicates emergency department; PCP, primary care physician; PECARN, Pediatric Emergency Care Applied Research Network; and PRAM, Pediatric Respiratory Assessment Measure.

${ }^{*}$ Appropriate medication measure.

†Documentation measure.

†Information provided at discharge measure.

PECARN performed a multisite study on management of closed head injury in pediatrics. ${ }^{24}$ 
Table 2. Top Measures From Resident Delphi Processes for Acute Asthma Exacerbation, Bronchiolitis, and Closed Head Injury

\begin{tabular}{|c|c|}
\hline Measure & Delphi Score (of 32) \\
\hline \multicolumn{2}{|l|}{ Acute asthma exacerbation } \\
\hline Appropriate medication dosing ${ }^{*}$ & 32 \\
\hline Documentation of work of breathing ${ }^{\dagger}$ & 31 \\
\hline Documentation of aeration/air exchange ${ }^{\dagger}$ & 31 \\
\hline Give albuterol prescription and make sure enough albuterol for home and school ${ }^{\ddagger}$ & 30 \\
\hline Presence or absence of wheezing documented ${ }^{\dagger}$ & 30 \\
\hline Ensuring patient sent home with steroid ${ }^{\ddagger}$ & 29 \\
\hline Reassessment documented in response to treatment $^{\dagger}$ & 27 \\
\hline Resident-assigned PRAM score matches resident-placed order ${ }^{\dagger}$ & 26 \\
\hline Appropriate discharge instructions ${ }^{\ddagger}$ & 26 \\
\hline Steroid ordered at same time or before albuterol/ipratropium ordered & 25 \\
\hline \multicolumn{2}{|l|}{ Bronchiolitis } \\
\hline Severity of respiratory distress documented ${ }^{\dagger}$ & 30 \\
\hline Oxygen saturation clearly documented in note ${ }^{\dagger}$ & 27 \\
\hline Appropriate discharge instructions ${ }^{\ddagger}$ & 25 \\
\hline Hydration status clearly documented in note ${ }^{\dagger}$ & 24 \\
\hline Reassessment documented after treatment/intervention ${ }^{\dagger}$ & 24 \\
\hline Diagnosis clearly explained to parents & 24 \\
\hline Day of illness clearly documented ${ }^{\dagger}$ & 22 \\
\hline Oral feeding tolerance clearly documented in note ${ }^{\dagger}$ & 22 \\
\hline Discharge papers document specific return to ED instructions (eg, work of breathing) ${ }^{\ddagger}$ & 20 \\
\hline Document birth history (preemie or not a preemie) ${ }^{\dagger}$ & 20 \\
\hline \multicolumn{2}{|l|}{ Closed head injury } \\
\hline Full neurologic examination documented ${ }^{\dagger}$ & 28 \\
\hline Thorough head examination (head, eyes, skull) documented ${ }^{\dagger}$ & 28 \\
\hline Time from arrival to appropriate intervention if increased intracranial pressure suspected & 27 \\
\hline Presence or absence of altered mental status documented ${ }^{\dagger}$ & 27 \\
\hline Presence or absence of loss of consciousness documented ${ }^{\dagger}$ & 26 \\
\hline Presence or absence of vomiting documented ${ }^{\dagger}$ & 24 \\
\hline Mechanism of injury documented ${ }^{\dagger}$ & 22 \\
\hline Does PECARN best practice alert recommendation match what was done for the patient? & 16 \\
\hline Guidelines given for return to play ${ }^{\ddagger}$ & 13 \\
\hline
\end{tabular}

PRAM indicates Pediatric Respiratory Assessment Measure; ED, emergency department; and PECARN, Pediatric Emergency Care Applied Research Network.

${ }^{*}$ Appropriate medication measure.

†Documentation measure.

†Information provided at discharge measure.

PECARN performed a multisite study on management of closed head injury in pediatrics. ${ }^{24}$

and information provided at discharge were commonly prioritized among both residents and supervisors.

\section{Focus Groups}

\section{Future SetTINGS AND Focus for RSQMS}

Residents noted that beyond the PED, HM and GP are the best settings in which to consider developing RSQMs. Focus group participants also noted considering these measures in the pediatric intensive care unit, neonatal intensive care unit, newborn nursery, and some inpatient subspecialty services. The commonly noted PED measures of appropriate medication use, documentation, and information provided at discharge were considered to be important in HM and GP as well.

In considering RSQMs beyond the PED, focus group participants felt the relative appropriateness of similar RSQMs varied based on setting. The most striking setting-related differences focused on resident autonomy and team-, compared with resident-, driven care. Residents felt they have high levels of autonomy in both the PED and HM. This autonomy was especially felt when making initial diagnoses and executing initial management plans for patients admitted overnight as well as completing care they felt did not need to wait until rounds. Like residents, supervisors also mentioned work done by residents overnight, focusing on the importance of residents discriminating necessary/unnecessary laboratory tests. In GP, there was concern that the team structure of resident continuity clinics served as a barrier to attributing care to an individual resident. For example, nurses may have immunizations ready before a resident orders them and common screenings (eg, developmental, autism) may be done by a nurse or a resident. Participants felt the acute care delivered in continuity clinics, however, is likely more attributable to a given resident.

Although the common PED measures such as medications, documentation, and discharge instructions were considered to be important in other settings, focus group participants raised concerns about the following exceptions: 1) appropriate medications may not be attributable to residents in HM, 2) since there is less documentation overall in GP, there is less available documentation to attribute to residents, 3) for GP, the established standards 
Table 3. Top Measures From Faculty/Fellow Delphi Processes for Acute Asthma Exacerbation, Bronchiolitis, and Closed Head Injury

\begin{tabular}{|c|c|}
\hline Measure & Delphi Score (of 36) \\
\hline \multicolumn{2}{|l|}{ Acute asthma exacerbation } \\
\hline Document response to intervention* & 35 \\
\hline 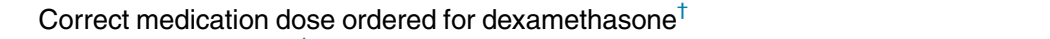 & 34 \\
\hline Use asthma order set ${ }^{\dagger}$ & 33 \\
\hline Correct medication dose ordered for albuterol $^{\dagger}$ & 32 \\
\hline Documentation of disposition decision* & 31 \\
\hline Note the acuity of the patient in documentation* & 30 \\
\hline Correct medication dose ordered for ipratropium $^{\dagger}$ & 28 \\
\hline Use of dexamethasone as steroid ${ }^{\dagger}$ & 28 \\
\hline Home dexamethasone instructions documented in discharge papers ${ }^{\ddagger}$ & 28 \\
\hline Use of standardized dosing for discharge medications (albuterol, dexamethasone) ${ }^{\dagger}$ & 28 \\
\hline \multicolumn{2}{|l|}{ Bronchiolitis } \\
\hline Assessment of severity documented ${ }^{\star}$ & 36 \\
\hline Effort of breathing documented* & 36 \\
\hline Follow pathway appropriately & 35 \\
\hline $\begin{array}{l}\text { Documentation of response to specific therapeutics (ie, how they responded to } \\
\text { suctioning, how they responded to breathing treatment, how they responded to } \\
\text { normal saline bolus, etc) }\end{array}$ & 32 \\
\hline Documentation of justification for appropriate disposition (home vs admit) ${ }^{*}$ & 31 \\
\hline Documentation of wheezing ${ }^{*}$ & 28 \\
\hline $\begin{array}{l}\text { Documentation of worsening respiratory symptoms as a reason to return in written } \\
\text { discharge instructions }{ }^{*}\end{array}$ & 25 \\
\hline Documented quality of air entry (normal, decreased, etc) ${ }^{*}$ & 24 \\
\hline $\begin{array}{l}\text { Documentation of poor feeding as a reason to return in written discharge } \\
\text { instructions }^{\ddagger}\end{array}$ & 22 \\
\hline \multicolumn{2}{|l|}{ Closed head injury } \\
\hline Documentation presence or absence of loss of consciousness ${ }^{*}$ & 36 \\
\hline Appropriate PECARN/closed head injury pathway use & 36 \\
\hline Documentation presence or absence of emesis* & 34 \\
\hline Mechanism of injury documented ${ }^{*}$ & 30 \\
\hline Full neurologic examination documented ${ }^{*}$ & 31 \\
\hline Documentation of GCS* & 31 \\
\hline Documentation of whether back to baseline or not ${ }^{*}$ & 31 \\
\hline Reassessments of patient documented ${ }^{*}$ & 28 \\
\hline Documentation of time of injury* & 27 \\
\hline Return to school/play recommendations in discharge papers ${ }^{\ddagger}$ & 22 \\
\hline
\end{tabular}

PECARN indicates Pediatric Emergency Care Applied Research Network; and GCS, Glasgow Coma Scale.

${ }^{*}$ Documentation measure.

†Appropriate medication measure.

‡Information provided at discharge measure.

PECARN performed a multisite study on management of closed head injury in pediatrics. ${ }^{24}$

for common care provided the opportunity to measure residents' adherence to these standards, and 4) for both HM and GP, use of standard (ie, pre-made) discharge instructions may lessen additional discharge instructions written by residents. However, for GP, participants thought it would be important for residents to add additional freetext instructions. Several potential foci for RSQMs in other settings were suggested, as detailed in Table 4. A number of these addressed care coordination, communication, and transitions of care.

\section{Differences in Proposed Measures Between Groups}

The resident NGT produced more measures than the supervisor NGT. Both focus groups felt this may be because residents work on the frontline and know more details of care provided there. As one resident noted, "we are the residents so we know," with other residents quickly offering affirmation.
Elaborating this further, both groups felt that residents tend to have detailed lists of care activities to complete, whereas supervisors focus more on the "big picture" care plan. Part of this was felt to be due to differences in the roles. However, supervisors also noted that residents may not be able to prioritize well or know resources available to help complete their work, and residents noted that supervisors may not know details that go into actually providing frontline care.

"They are the ones who are actually doing this stuff. . . and I think for many of us we don't have to do a lot of those steps." (HM faculty)

Supervisors "don't know the system. . to make sure the patient is taken care of (group laughing)." (resident)

Both focus groups spoke to why residents may provide more specificity in discharge instructions. They agreed 
Table 4. Potential RSQMs for Other Settings Noted in Focus Groups

\begin{tabular}{|c|c|}
\hline Additional Setting & Potential RSQMs \\
\hline \multirow[t]{9}{*}{ General pediatrics } & Diagnosis entered by resident \\
\hline & $\begin{array}{l}\text { Preventive care at health supervision visits (eg, immunizations given, } C B C \text {, lead level, social risk } \\
\text { screening such as food insecurity, maternal depression, developmental screening, autism screening) }\end{array}$ \\
\hline & Refer patients with developmental delays \\
\hline & Medication reconciliation \\
\hline & Efficiency/patients seen per clinic \\
\hline & Chronic illness management (eg, asthma action plan) \\
\hline & Documenting counseling on vaccines and development \\
\hline & Add free text instructions to discharge papers \\
\hline & Provide standard age-based discharge instructions for health supervision visits \\
\hline \multirow[t]{2}{*}{$\mathrm{NICU}$} & Communication with primary care physician \\
\hline & Handover to the PCP at discharge \\
\hline \multirow[t]{5}{*}{ PICU } & PICU component of hospital stay documented in discharge summary living document \\
\hline & Nonemergent orders (but these are checked closely, so may or may not represent resident action) \\
\hline & Handover to floor team \\
\hline & Call primary care physician upon admission \\
\hline & Effective handovers to hospital medicine team \\
\hline \multirow[t]{3}{*}{ Newborn nursery } & Newborn checklist items \\
\hline & Order hepatitis B immunization \\
\hline & Order hearing screen \\
\hline \multirow[t]{15}{*}{ Hospital medicine } & Effective interdisciplinary communication captured on secure messaging and text paging services \\
\hline & Call consult before talking with attending if appropriate \\
\hline & Effective handovers \\
\hline & Keep primary care physician updated during hospitalization \\
\hline & Call primary care doctor at discharge \\
\hline & Discharge planning/have discharge prepped \\
\hline & Effective communication with consultants to ascertain the input needed \\
\hline & Translating consultant recommendations into care \\
\hline & Calling consults before talking with the attending \\
\hline & Communicating plans of care with the inter-disciplinary team members \\
\hline & Thorough handovers to other team members \\
\hline & Handover to the PCP at discharge \\
\hline & Medication reconciliation \\
\hline & Concise and effective discharge summary \\
\hline & Document contingency planning \\
\hline \multirow[t]{2}{*}{ GI } & Orders \\
\hline & Documentation \\
\hline \multirow[t]{2}{*}{ Cardiology } & Orders \\
\hline & Documentation \\
\hline \multirow[t]{2}{*}{ Hematology/oncology } & Orders \\
\hline & Documentation \\
\hline Most Specialties & Ensuring that families are kept updated and educated \\
\hline
\end{tabular}

RSQM indicates resident-sensitive quality measures; $\mathrm{CBC}$, complete blood count; PCP, primary care physician; NICU, neonatal intensive care unit; PICU, pediatric intensive care unit; and GI, gastrointestinal.

that less experience among residents means less knowledge of what may or may not happen after discharge; therefore, residents may strive to provide more detail for families to ensure that all relevant information is covered.

"Residents just don't know what is going to happen...they don't have the experience. . .so they worry [and] think "we have to put in all or our own discharge instructions' instead of using common ones" (HM faculty)

Both groups also felt that residents may not know all standard discharge instruction templates, with residents adding they may not know their content even if they know they exist, due to rotating from one setting to another. Thus, residents may be more likely to write these details out, compared with supervisors, who may provide a single proposed RSQM of "provide standard discharge instruction template." However, residents also noted they are often the last physician contact with families before discharge. Therefore, they feel a greater need to cover every detail possible and personalize instructions to ensure an effective discharge, adding that they edit and add to standard discharge instructions when they feel important information is missing.

"The templates look nice...but...looking at them I think, 'OK, the family would think this is standard and this doesn't apply to my kid'...I want to hear about what the doctor thinks personally...that's why we take the time to do that." (resident)

Finally, both groups articulated a high level of importance for providing RSQMs to residents. Residents felt RSQMs would provide them with feedback to help drive 
personal improvement, insights into whether their patients are actually receiving quality care from them, and a meaningful role in quality improvement where they may not otherwise have one. They also noted that objective measures for tracking global improvement throughout training and accurate assessments of their performance are lacking on many rotations. Similar to residents, supervisors noted that RSQMs can provide a more objective way of assessing residents, that feedback on performance drives improvement, and that data drive change. They also noted that the Accreditation Council for Graduate Medical Education requires residents to receive data on their performance and RSQMs can achieve that goal.

"If you had objective measures, you...[could] look back...and really see like what went wrong, what could be improved." (resident)

As an "attending...we get some QI data back. With resident[s], I believe they get very minimal, if any, and then we expect them to improve." (GP faculty)

\section{Discussion}

This study provides insights into differences between RSQMs developed by residents and supervisors and highlights considerations for developing RSQMs in settings beyond the PED, both of which should be considered in the ongoing development of RSQMs.

\section{Measures Important to Residents and Supervisors}

Both residents and supervisors, in consensus groups and subsequent focus groups, placed considerable focus on appropriate medication dosing, documentation, and information provided at patient discharge. Medication dosing is foundational to safe care, and medication errors in teaching hospitals are well-described, common, and significant. ${ }^{25,26}$ We believe that accurate documentation demonstrates appropriate knowledge, medical decisionmaking, and attention to importance of charting in communication. It also acknowledges the medico-legal importance of documentation. Finally, information provided at discharge is important to not only ensure continued highquality management and care after discharge but also to prevent unnecessary returns seeking additional care, a known problem. ${ }^{27}$ With this need, the National Quality Forum has developed quality measures with this focus. ${ }^{28}$ Given these types of measures are valued by both consensus group and focus group participants, we believe future RSQM development should pay attention to this area.

\section{Considerations for Future RSQM Development}

Residents felt that HM and GP are settings of high utility for future RSQM development and should receive prioritization in developing future RSQMs. However, residents and supervisors alike highlighted important nuances in evaluating the fit of RSQMs in different settings and their importance for RSQM development as the process extends into new clinical settings. This finding likely underscores the importance of continuing to develop RSQMs primarily in specific settings rather than seeking global measures for use across settings.

Consensus group participants developed and prioritized similar as well as contrasting measures between residents and supervisors. Subsequent focus groups with these stakeholders showed common rationales for putting forth the measures they did but also offered distinct insights. These findings may indicate "blind spots" possessed by each group for certain areas of resident care processes and work. The presence of these blind spots highlights the relative value of engaging both stakeholder groups in developing future RSQMs. Importantly, however, both resident and supervisor focus group participants felt that residents provided both more potential and more specific RSQMs because they understand the work they are doing at the frontline better than supervisors.

\section{Potential Value of RSQMs for Residents}

Finally, some of the measures produced by residents in their NGT may emphasize the depth of performance data and feedback they desire about patients they have cared for, including returns to the PED. A recent study underscores that resident experiences with quality improvement are far from ideal, including residents not understanding the vision of quality improvement and feeling they are not valued or valuable in the quality improvement process. ${ }^{29}$ The types of metrics developed by residents seem to indicate that they are eager for outcome measures related to the care they provide. Although not an intended focus of our study at the outset, these comments were impossible to ignore and therefore formed a focus of investigation in the subsequent focus groups we conducted. This exploration revealed that RSQMs were perceived to be important in providing feedback that can drive improvement and overcome suboptimal performance assessment practices by providing objective data on resident performance.

\section{LiMITATIONS}

This study has limitations to consider. First, it was conducted at a single institution. Different measures may have been put forth by individuals at another institution. Although we believe that most of the measures developed in this study would apply across institutions, implementation studies will need to investigate whether this is true as well as learn how these measures perform as markers of resident performance. Second, although this work engaged 2 stakeholder groups (supervisors and residents), it did not seek to develop measures among additional stakeholders, such as nurses, patients, and families. Future work should develop and compare measures that would be set forth by these groups. Third, between the NGT and Delphi groups, we deleted the few proposed measures that could not be extracted from the EHR as we did not anticipate such measures being named. Finally, we did not seek the level of clinical experience for residents in this study, which could impact the input they provide. 
However, it should be noted that all NGT and Delphi resident participants needed to have PED experience to participate and all resident focus group participants, by the nature of timing for the focus group, were beyond intern year. Despite the limitations of this study, it does avoid common pitfalls in consensus group work, such as not describing background information for participants and not defining consensus a priori. ${ }^{23}$

\section{Conclusions}

RSQMs can continue to advance competency-based medical education efforts where the link between educational outcomes (ie, what an individual can do at the end of training) and patient care outcomes (ie, how well patient care needs are met) is both elusive but also key to advancing care quality. ${ }^{30,31}$ This study continues to pave the path forward in developing future RSQMs by exploring specific settings, methods, measures, and stakeholders to consider when undertaking this work.

\section{ACKNOWLEDGMenTS}

Financial disclosure: This study was supported by a Place Outcomes Research Award at Cincinnati Children's as well as by the Division of Emergency Medicine at Cincinnati Children's.

\section{SuPPlementary Data}

Supplementary data related to this article can be found online at doi:10.1016/j.acap.2018.09.013.

\section{References}

1. van der Leeuw RM, Lombarts KM, Arah OA, et al. A systematic review of the effects of residency training on patient outcomes. BMC Med. 2012;10:1.

2. Asch DA, Nicholson S, Srinivas S, et al. Evaluating obstetrical residency programs using patient outcomes. JAMA. 2009;302:1277-1283.

3. Bansal N, Simmons KD, Epstein AJ, et al. Using patient outcomes to evaluate general surgery residency program performance. JAMA Surg. 2016;151:111-119.

4. Chen C, Petterson S, Phillips R, et al. Spending patterns in region of residency training and subsequent expenditures for care provided by practicing physicians for Medicare beneficiaries. JAMA. 2014;312:2385-2393.

5. Sirovich BE, Lipner RS, Johnston M, et al. The association between residency training and internists' ability to practice conservatively. JAMA Intern Med. 2014;174:1640-1648.

6. Phillips RL, Petterson SM, Bazemore AW, et al. The effects of training institution practice costs, quality, and other characteristics on future practice. Ann Fam Med. 2017;15:140-148.

7. MedPAC. Graduate medical education financing: Focusing on educational priorities. In: Report to Congress: Aligning Incentives in Medicare. Washington, DC: Medicare Payment Advisory Commission. 2010:103-126.

8. Cordasco K, Horta M, Lurie N, et al. How Are Residency Programs Preparing Our 21st Century Internists? A Review of Internal Medicine Residency Programs' Teaching on Selected Topics. RAND Corporation, Working Paper, 2009. Available at: www.rand.org/content/dam/ rand/pubs/working_papers/2009/RAND_WR686.pdf. Accessed January 2009.
9. Medicare Payment Advisory Commission. Report to the Congress: improving incentives in the Medicare program. June 2009. Available at: http://www.medpac.gov/docs/default-source/reports/Jun09_EntireReport.pdf. Accessed Oct 31, 2018.

10. Wiest FC, Ferris TG, Gokhale M, et al. Preparedness of internal medicine and family practice residents for treating common conditions. JAMA. 2002;288:2609-2614.

11. Kalet AL, Gillespie CC, Schwartz MD, et al. New measures to establish the evidence base for medical education: identifying educationally sensitive patient outcomes. Acad Med. 2010;85:844-851.

12. Cook DA, West CP. Reconsidering the focus on "outcomes research" in medical education: a cautionary note. Acad Med. 2013;88:162-167.

13. Swing SR, Schneider S, Bizovi K, et al. Using patient care quality measures to assess educational outcomes. Acad Emerg Med. 2007; 14:463-473.

14. Haan CK, Edwards FH, Poole B, et al. A model to begin to use clinical outcomes in medical education. Acad Med. 2008;83:574-580.

15. Yin HS, Jay M, Maness L, et al. Health literacy: an educationally sensitive patient outcome. J Gen Intern Med. 2015;30:1363-1368.

16. Moreau KA, Eady K. Connecting medical education to patient outcomes: the promise of contribution analysis. Med Teach. 2015;37: 1060-1062.

17. Van Melle E, Gruppen L, Holmboe ES, et al. Using contribution analysis to evaluate competency-based medical education programs: it's all about rigor in thinking. Acad Med. 2017;92:752-758.

18. Schumacher DJ, Holmboe ES, van der Vleuten C, et al. Developing resident-sensitive quality measures: a model from pediatric emergency medicine. Acad Med. 2018;93:1071-1078.

19. Creswell J. Educational Research: Planning, Conducting, and Evaluating Quantitative and Qualitative Research. 6th ed. Upper Saddle River, NJ: Pearson; 2019.

20. Mittiga MR, Schwartz HP, Iyer SB, et al. Pediatric emergency medicine residency experience: requirements versus reality. J Grad Med Educ. 2010;2:571-576.

21. Humphrey-Murto S, Varpio L, Wood TJ, et al. The use of Delphi and other consensus group methods in medical education. Acad Med. 2016;91:S11.

22. Hsieh HF, Shannon SE. Three approaches to qualitative content analysis. Qual Health Res. 2005;15:1277-1288.

23. Hsu CC, Sandford BA. The Delphi technique: making sense of consensus. Pract Assess Res Eval. 2007;12(10).

24. Kuppermann N, Holmes JF, Dayan PS, et al. Identification of children at very low risk of clinically-important brain injuries after head trauma: a prospective cohort study. Lancet. 2009;374:1160-1170.

25. Taylor BL, Selbst SM, Shah AE. Prescription writing errors in the pediatric emergency department. Pediatr Emerg Care. 2005;21:822-827.

26. Lewis PJ, Dornan T, Taylor D, et al. Prevalence, incidence and nature of prescribing errors in hospital inpatients. Drug Safety. 2009;32:379-389.

27. Navanandan N, Schmidt SK, Cabrera N, et al. The caregiver perspective on unscheduled 72-hour return visits to pediatric acute care sites: a focus on discharge processes. Acad Pediatr. 2017;17:755761.

28. The CTM-15 and CTM-3. 2018. Available at: https://caretransitions.org/tools-and-resources/. Accessed August 30, 2018.

29. Butler JM, Anderson KA, Supiano MA, et al. "It feels like a lot of extra work": resident attitudes about quality improvement and implications for an effective learning health care system. Acad Med. 2017;92:984-990.

30. Carraccio C, Englander R, Holmboe E, et al. Driving care quality: aligning trainee assessment and supervision through practical application of entrustable professional activities, competencies, and milestones. Acad Med. 2016;91:199-203.

31. Gruppen L, Frank JR, Lockyer J, et al. Toward a research agenda for competency-based medical education. Med Teach. 2017;39:623-630. 